\title{
An analysis of the factors for educational game design based on mobile platform
}

\author{
Zhe Ji \\ Xiamen University of Technology \\ No.600 Ligong Road, Jimei District, Xiamen, 361024, Fujian Province, China \\ jizhe@xmut.edu.cn
}

Keywords: Mobile, Educational games, game design

\begin{abstract}
Digital games have been playing an important role around our lives, including the aspects of learning and education. The way of teaching of digital games can effectively motivate the learners, acting a good supplement of traditional way. With the innovation of technology and popularization of mobile devices, digital games which based on this are getting accepted and widely spread. It can improve the hand-eye coordination and the abilities of thinking and decision-making, developing abstract thinking and reasoning etc. This article based on the aspects of learning, instructional design, games design to develop a digital game containing education and entertainment combining with touch screen mobile devices. The purposes are to dig out the attractive points of game design for learner and integrate the educational strategy into game design.
\end{abstract}

\section{Introduction}

Educational game makes the learning process interesting and can cultivate students' abilities of high-order thinking. Students participate various kinds of learning activities integrated in games to accept challenges and thinking actively to resolve conflicts, rather than being inculcated knowledge passively. Prensky ${ }^{[1]}$ ( 2005) believe that computer games can both train your skills and concentration, providing learning motivation, offering rich learning content to enhance learning function to release teachers' pressure. Hogle (1996) once raises the advantages of game-based learning: promote learning motivation and interest, extend the retention time of memory, more chances to practice and feedback to step to higher -level thinking.

The mobile devices mentioned in this paper contain smart phone and tablet computer. In general, the games run in the smart phone and tablet computer are called mobile games. Games based on mobile platform mean handheld game and mobile game in this paper. Nowadays, there is a sharp increase in people who using mobile platform. Easy operation is the prominent advantage of mobile platform game and our users just need fingers to process click contact which makes preschool children and old people with descending memory experience the joy of game, this is why online game is irreplaceable. This product get over the disadvantage of taking online game on the table's inconvenient and plug-in electric all the time.

The rest of the article is organized as follows. Section 2 is a summary of several concepts and researches of current educational game design. Section 3 will propose a design frame of educational games based on mobile platform. Section 4will give an explanation to the methods mentioned above by analyzing an under-developing game. Conclusion will be made in Section 5.

\section{Educational game design}

\subsection{Educational games}

Relevant fact is shown by Vargas ${ }^{[2]}$ who states that in a systematic search, $60.71 \%$ of serious games belong to the educational sphere. Educational game is a kind of serious games ${ }^{[3,4]}$, which is developed for particular educational purposes with equal attention to game and education. Educational games are gamesthat are designed to help people to learn about certain subjects, expand 
concepts, reinforce development, understand a historical event or culture, or assist them in learning a skill as they play. Games are interactive play that teach us goals, rules, adaptation, problem solving, interaction, all represented as a story. ${ }^{[5]}$

\subsection{Digital game design}

For the ones who are not familiar with modern game R\&D, they often use "game design" to cover all kinds of professional work during development. Work can be normally divided into below: planning, artistic designing, program designing, music and sound, testing. This paper considers that the main elements of educational game include the object of game, plot, game rules, interaction design, artistic designing, which can be references during game design including operating platform, story, type, battle and connection mode. Furthermore, as to the artistic design phase, can be specified to game content design, animation design, interface design, scenario design, character design and so on.

\subsection{Instructional system design}

Instructional design is a process instructors fulfill it by applying kinds of learning related knowledge and theories, which is combined with teaching theories and practical planning teaching activities, and including the influence factors consideration during the period. Instructional design contains activities of planning, selection, preparation, practice and evaluation etc. The main purpose is to improve learners' efficiency by participating designed and arranged learning situation.

A famous model ADDIE ${ }^{[6]}$ is often mentioned during the programmable teaching design. Five letters respectively represent Analysis, Design, Development, Implementation and Evaluation. ADDIE is a model of instructional system design (ISD), can be spilt into five stages, stated as below(Strickland,2006): analysis, design, development, implementation and evaluation.

As for this paper, if it's only for designing of digital games on mobile platform, this model still need to be improved, for example how to make a good connection between instructional design and game design.

The principle of educational game design is to integrate learning into the setting and purpose of game, compromising the process of educational system design and digital game design. Fabricatore $^{[7]}$ raised a design method called Edugaming, advocating mixture of learning task and related game scenario. According to this research, principles below can be referred when designing game structure.(1)Diversity of game style.(2)Moderate difficulty of game.(3)Fair and simple game principle.(4)Take both process and result of game into consideration.(5)Balance between capability and good luck.

\section{Design factors analysis to educational game}

Framework design of educational games mentioned in this paper takes above factors as guideline, mobile devices as platform, based on the cognitive characteristics of learners to carry on an analyst. This model(fig1.) separates the design cycle of educational game into basic competences and educational objectives, design of the type of the game, design of the scenario, design of the game rule, design of the game elements, and educational assessment. There are six periods in total, which contain corresponding design task.

\subsection{Pre-phase 1.Education design}

In this first phase, the main task during this phase is to get the basic competences and objectives of learners to be confirmed, design main learning task. Model in this phase contains four tasks: game requirement analyst, learners' cognitive characteristics analyst, learning content design and target confirm.

\subsection{Pre-phase 2.Design of the type of game}

Operation platform, game theme, game genre, battle mode, perspective of game, interaction will be designed in this phase. This part belongs to primary design. For example, the classification of ${ }^{[8]}$ could be used to determine the video game genre (e.g. action, adventure, fight, logic, simulation, sport, strategy, etc.). 


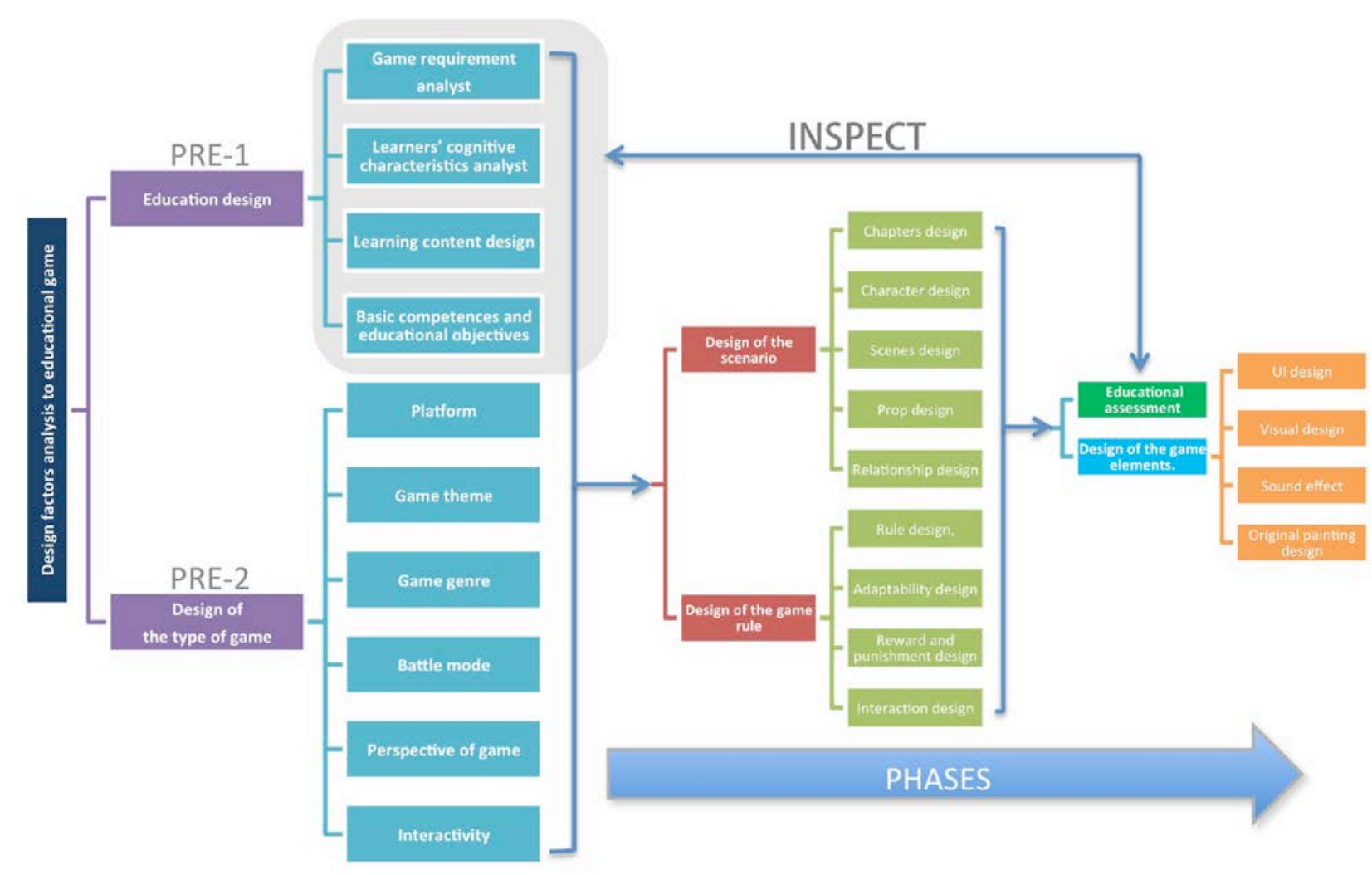

Fig.1:Design Factors analysis to educational game

\subsection{Design of the scenario}

Five aspects of, chapters design, scenes design, character design, prop design, relationship between players will be in the period. Chapters design and Scenes design is to create an interesting detailed story integrated with learning content based on learning target. Character design creates a virtual role controlled by learner to achieve the goal in the game. Prop design provides appropriate tools for game roles to solve problems based on target of game. Relationship design is to create interactive connection between roles to solve higher-level problem, which make learners get a balance between task and skill.

\subsection{Design of the game rule}

Design in this period contains rule design, adaptability design, reward and punishment design. These three parts by capturing players' behavior, adjust interface changing of game and consequence feedback based on this. Besides, there are two kinds of interaction design: HMI between learns and roles in the game or among roles. Different interaction between roles will be formed based on relationship including task assignment, reminder giving, breakthrough making, competition, cooperation and coordination etc.

\subsection{Design of the game elements}

Elements design contains UI design, visual design, sound effect design, original painting design etc. The former one supports all kinds gaming behavior of roles, the latter one is an area filled with learning results after specified action being implemented by roles. Visual design is trying to make an emotional and cognitive influence on learners by changing the color, brightness, Layout of game interface. Sound effect design means different sound notification accompanying with different operational behavior. Or generate different background music when coming into different scenario, by changing which to send notification and feedback.

\subsection{Educational assessment}

This part is aim to evaluate the contact of educational game target. To ensure which target and ability even which key teaching points should be evaluate by educators team. The level of evaluate can decided by achieving condition in the scene and the collecting data which are from player's achieving target and using time and so on in accomplishing the teaching project. 


\section{Case study}

We are designing an educational game in the name of " Idioms Champion" that based on the principles above. in a mini story as an example. It's a Chinese idioms educational game designed for 9-13 year old students. Through the course of the game, the students can understand Chinese idioms from the interpretation of four-word idioms and idioms related stories which is a useful supplement for learning Chinese language.

\subsection{Education design}

We are designing an educational game in the name of Idioms Champion that based on the principles above in a mini story as an example. It's a Chinese idioms educational game designed for 9-13 years old students.The educational team has grouped into four categories: literal comprehension, inferential comprehension, critical understanding, global understanding.

\subsection{Design of the type of game}

This game takes smart phone and computer tablet as a running platform, while its visual style is 2D graphic that based on touch screen. Players have to get through several barriers and obtain the champion to save his mum's life in the game where he acts as a little boy or little girl in the ancient world.

\subsection{Design of the scenario}

\subsubsection{Chapters design}

The game consists of several chapters, each chapter will have 3-5 mini idioms story.The relationship between the chapters will be getting progressive, gradually increasing the difficulty. Players must have a deep understanding of the four-word idioms at each level to finally finish the game.We will take an idiom Mini story as a demonstration in this sector, which is so-called "Covering One's Ears While Stealing a Bell”. There was once someone who wanted to steal a clock in the Spring and Autumn Period, can't move it cause the clock is too big and heavy, then he wanted to crack it with a hammer and resulted a huge bell sound, the person worried that others heard the voice, so he covered their ears continue to hit the bell. According to the original story, the players may need:(1)The game player goes to Jin to find his mum, he finds a customs clearance idiom card which writes "Fan's house ".(2)The player comes to Fan's house where he meets the person stealing the clock, it happens to help him find the Fan's clock.(3)Complete the idiom answer and save the person, and get the clock props.(4)Complete the definition of the idiom and choose the idioms by the same category, Finish this mini story by getting the idiom card.

\subsubsection{Scene design}

The scene is where the role's action and dialogue takes place in the game, and it usually includes static and dynamic two different sections. We need to design the distant view of Jin, the street view close to the gate of Fan's house, and also the Pavilion where hangs the Bell etc..

\subsubsection{Character and props design}

Absolutely, the original image design can be adopted by the protagonist. However, we should also consider the passers-by's role design, and the clock and idiom card should be the main props used in the game.

\subsection{Design of the rules}

The game is divided into three kinds of difficulty levels, which are simple, general and high-level, so it be adapted to the players with different knowledge and skills. If the learners can not complete the current task, the system will give tips or reminders to reduce the difficulty of the game. This game's reward and punishment design is through the integral increase or decrease, the medal, props to provide timely feedback to the players.

\subsection{UI design}

The interface of the game is divided into the game area and feedback area, while the feedback area is located in the upper and left side to display the current state of the game. When a task is completed, the feedback area on the top will show the progress, and also the number of levels and scores. We can find the idiom card collection box and the item collection box in the left feedback area . 


\section{Conclusion}

We proposed a framework for educational games to further improve the education game teaching effect, and introduced the factors, design steps and design method for the educational game, and applied them in an idiom game. The design process is divided into five steps based on the learning objectives, teaching design and game design.

In the three aspects of learning objectives, teaching design and game design as the foundation, the design process is divided into five stages, including the analysis of the model, basic ability and education target type of game design, game scene design, the rules of the game design and game design elements in five stages.

We will continue to work on the design of this educational game, and keep our further research on the aspects of teaching efficiency, game setting, game quality, and emotional design. We will test the final product with real players to measure their experience or interest about the appearance of new challenges, characters and scenarios.

\section{References}

[1] Prensky, M. In digital games for education, Complexity matters, Educational Technology, 45(4) (2005), 22-28,

[2] J.A. Vargas, L. García-Mundo, M. Genero, M. Piattini, A systematic mapping study on serious game quality, in: Proceedings of the 18th International Conference on Evaluation and Assessment in Software Engineering, ACM, 2014.

[3] T.M. Connolly, E.A. Boyle, E. MacArthur, T. Hainey, J.M. Boyle, A systematic literature review of empirical evidence on computer games and serious games, Comput. Educ. 59 (2) (2012) 661-686.

[4] M. Zydaulation to virtual reality to games, Co25-32.

[5] Educational game, https://en.wikipedia.org/wiki/Educational_game

[6] Strickland, A. W. (2006). ADDIE. Idaho State University College of Education, ichesience, Math \& Technology Education. itspep?

[7] Fabricatore, C., Nussbaum, M., \& Rosas, R., Playability in action videogames: A qualitative design model. Human-Computer Interaction, 17(4)(2002), 311-368.

[8] J.C. Herz, Joystick Nation: How Videogames Ate Our Quarters, Won Our Hearts, and Rewired Our Minds, Little, Brown and Company, Boston, 1997. 